\title{
ENEM, TEMAS ESTRUTURADORES E CONCEITOS UNIFICADORES NO ENSINO DE FÍSICA
}

\author{
Wagner Duarte José * \\ Graciely Rocha Braga ** \\ Ana Quézia Brito Nascimento ** \\ Fábio da Purificação de Bastos ***
}

RESUMO: A adoção do Exame Nacional do Ensino Médio (Enem) pelas universidades públicas vem redimensionando as políticas públicas de acesso e permanência no ensino superior. Para o ensino de física, isso potencializa a problematização do conhecimento desta disciplina. Neste trabalho, investigamos as questões de Ciências da Natureza e suas Tecnologias relacionadas à física das edições do Enem de 2009 a 2012. A contextualização está muito presente em aspectos do cotidiano e do par ciência-tecnologia. Os temas "calor, meio ambiente e usos da energia" e "equipamentos elétricos e telecomunicações" articulam a interdisciplinaridade e a contextualização, privilegiando a abordagem conceitual unificadora, mas estão perdendo espaço para o tema "movimento, variações e conservações". Nas análises, revelamos aspectos essenciais para o trabalho escolar interdisciplinar e contextualizado, preconizado pelos Parâmetros Curriculares Nacionais. Palavras-chave: Enem. Temas estruturadores do ensino de física. Conceitos unificadores.

\section{ENEM, STRUCTURAL THEMES AND UNIFYING CONCEPTS FOR PHYSICS TEACHING}

ABSTRACT: The adoption of the National Standard Exam of Middle School (ENEM) by Public Universities has been reconfiguring public policies of access and permanence in High Education. For the teaching of Physics, it enhances the discussion of the knowledge of this subject. In this paper, we investigate the items of evaluation of Natural Sciences and Their Technologies related to Physics in the editions of ENEM from 2009 to 2012. The contextualization is presented in aspects of daily life and science-technology pair. The themes "heat, environment and uses of energy" and "electrical devices and telecommunications", though losing space for the theme "movement, variation, conservation", where the highlighted key aspects for interdisciplinary and contextualization with focus on a conceptual-unifying approach. In the analysis, we emphasize on essential aspects for interdisciplinary and contextualized work for school, as recommended by the board for national-standard exams.

Keywords: Enem. Structural themes for the teaching of physics. Unifying concepts.

DOI - http://dx.doi.org/10.1590/1983-21172014160308

Revista Ensaio | Belo Horizonte | v.16 | n. 03 | p. 171-188 | set-dez | 2014 


\section{INTRODUÇÃO}

A adoção do Exame Nacional do Ensino Médio (Enem) pelas universidades públicas federais e estaduais vem redimensionando as políticas públicas de acesso e permanência no ensino superior, tendo-se como pano de fundo o avanço científico-tecnológico, a parametrização curricular nacional e as profundas transformações na sociedade e no mundo do trabalho. A partir das provas de 2009, criou-se um novo formato, e o Enem passou a promover a avaliação do desempenho acadêmico dos estudantes ingressantes nas Instituições de Educação Superior, ao que o Ministério da Educação (MEC) chamou de novo Enem.

O novo Enem propõe articular a educação básica com o ensino superior a partir de uma matriz de referência e de objetos de conhecimento (MACENO et al., 2011; PEIXOTO; LINHARES, 2010). Isso significa que a universidade, especialmente os cursos de formação de professores, pode, em muito, contribuir para as mudanças no Ensino Médio, conforme preconizam as diretrizes e os Parâmetros Curriculares Nacionais (PCN) da educação brasileira.

No que se refere aos conhecimentos de física, a via de acesso à universidade através do Enem potencializa a discussão em torno do seu ensino. Verificar de que forma a física está sendo inserida nas provas do Enem contribui para problematizar os conteúdos e a sua abordagem, tanto no Ensino Médio como na formação inicial em cursos de licenciatura.

Neste trabalho, investigamos as questões e os conhecimentos relacionados à física presentes nas provas de Ciências Naturais e suas Tecnologias nas edições de 2009 a 2012 do Enem. Objetivamos verificar se são articulados os princípios de interdisciplinaridade ${ }^{1}$ e contextualização ${ }^{2}$, os Temas Estruturadores ${ }^{3}$ do Ensino de Física (TEEF) e o conceito unificador" "energia" da abordagem conceitual unificadora. Nossa meta foi destacar a potencialidade dessa articulação para o ensino-aprendizagem segundo a via dos universais da física, tendo em vista a inserção curricular da resolução aberta de problemas do Enem e suas contribuições para a educação científico-tecnológica.

\section{$1{ }^{\text {a PROBLEMATIZAC̣̃̃O }}$}

Realizado pelo Instituto Nacional de Estudos e Pesquisas Educacionais Anísio Teixeira (Inep), o Enem foi instituído em 1998, a fim de avaliar o desempenho do estudante egresso do Ensino Médio a partir da análise de situações-problema, explorando as competências e as habilidades preconizadas nos documentos oficiais (BRASIL, 1999, 2002).

Além de resultar em diagnóstico e feedback de avaliação deste nível de ensino, auxiliando na elaboração de políticas de melhoria da educação brasileira, o Enem também possibilita o acesso a diversos programas governamentais, como o Programa Universidade para Todos (ProUni) - desde 2005 -, além de seu 
resultado ser avaliado para ingresso de estudantes nas instituições de ensino superior particulares e, mais recentemente, por meio do Sistema de Seleção Unificada (Sisu), em universidades públicas e institutos federais. O Enem é um exame

\begin{abstract}
individual e de caráter voluntário, oferecido anualmente aos concluintes e egressos do Ensino Médio, com o objetivo principal de possibilitar uma referência para autoavaliação, a partir das competências e habilidades que o estruturam. Além disso, ele serve como modalidade alternativa ou complementar aos processos de seleção para o acesso ao ensino superior e ao mercado de trabalho. Realizado anualmente, ele se constitui um valioso instrumento de avaliação, fornecendo uma imagem realista e sempre atualizada da educação no Brasil (INEP, 2005, p. 7).
\end{abstract}

A Portaria nº. 807/2010 do Ministério da Educação (2010) conferiu ao Enem objetivos de certificação de conclusão do Ensino Médio e de servir como "referência nacional para o aperfeiçoamento dos currículos do Ensino Médio", ampliando ainda mais sua importância (MIRANDA et al., 2009).

Interdisciplinaridade e contextualização, princípios basilares dos Parâmetros Curriculares Nacionais do Ensino Médio (PCNEM), verticalizam a prova no sentido da construção do conhecimento para a vida autônoma e suscitam relações horizontais integradoras das várias áreas do conhecimento, associando conteúdos, competências e habilidades adquiridas na escola (MIRANDA et al., 2009; PEIXOTO; LINHARES, 2010).

As questões da prova de Ciências da Natureza e suas Tecnologias (CNT) do Enem versam sobre conhecimentos de física, química e biologia, a partir de uma Matriz de Referência, avaliando oito competências e 30 habilidades que se entrelaçam (BRASIL, 2009). Peixoto e Linhares (2010) analisaram as 45 questões da primeira prova de CNT, aplicada em 2009 com o novo formato, e pontuaram aspectos importantes para a consolidação do novo Enem:

1. A contextualização continua presente no exame; a interdisciplinaridade ocorre em menor grau, através de temas abrangentes integrando conceitos de diferentes disciplinas;

2. As questões de física exigiram um conhecimento mais aprofundado da matéria em relação aos anos anteriores, mas não através de aplicações de fórmulas; a abordagem conceitual esteve presente e relacionada a situações reais;

3. O novo formato do Enem é um exemplo de avaliação que pode ser praticada no contexto escolar de maneira mais formativa, que precisa ser enfatizada na prática didático-pedagógica, orientada para o desenvolvimento de competências e habilidades.

Esses autores analisaram ainda as questões de física da prova do Enem2010 e verificaram sua justaposição com a organização curricular de Ciências da Natureza adotada pela Secretaria Estadual de Educação do Rio de Janeiro. Ao concluírem, defenderam as potencialidades das questões relacionadas à física para a promoção de aprendizagens (PEIXOTO; LINHARES, 2011). 
Recentemente, Hernandes e Martins (2013) realizaram um estudo minucioso das provas de CNT dos anos 2009 a 2011, no qual descreveram como as questões relacionadas à física incorporam as competências da área preconizadas na Matriz de Referência do novo Enem. Os autores revelaram a forte correlação das questões analisadas com as Orientações Complementares aos PCNEM (chamadas de $\mathrm{PCN}+$ ), mas observaram nuances da abordagem tradicional da física. Devemos enfatizar que o trabalho de Hernandes e Martins (2013) é seminal em destacar/sugerir em que contextos e com quais finalidades as questões do novo Enem podem ser inseridas nas atividades escolares.

Segundo as orientações para a elaboração de provas do Enem, suas questões representam situações codificadas cuja solução espera do estudante uma intervenção a partir da projeção de fatos cotidianos e de demonstrações práticas nas quais utilizem conhecimentos disciplinares de forma mais qualitativa (INEP, 2005), em comum acordo com os PCN+ (BRASIL, 2002).

Diferentemente das avaliações de física pautadas em exercícios de aplicação, uma questão do novo Enem, de acordo com o contexto nela descrito, pode ser classificada segundo o quadro abaixo (COSTA-BEBER; MALDANER, 2012):

Quadro 1: Classificação das questões do novo Enem segundo a contextualização.

\begin{tabular}{|c|c|c|}
\hline Contextualizada & $\begin{array}{c}\text { Parcialmente } \\
\text { contextualizada }\end{array}$ & Não contextualizada \\
\hline $\begin{array}{c}\text { Quando os conteúdos } \\
\text { relevantes inserem-se } \\
\text { numa situação codificada } \\
\text { dentro de um contexto bem- } \\
\text { delimitado, necessário ao } \\
\text { entendimento do problema, } \\
\text { e cuja solução está definida } \\
\text { tendo os conteúdos } \\
\text { parcialmente na situação } \\
\text { codificada, representando } \\
\text { um contexto que serve } \\
\text { como ilustração ou } \\
\text { esclarecimento e, via de } \\
\text { regra, pouco contribui para a } \\
\text { solução da questão. }\end{array}$ & $\begin{array}{c}\text { Quando os conteúdos } \\
\text { relevantes não se relacionam } \\
\text { com um contexto definido }\end{array}$ \\
\hline
\end{tabular}

Fonte: Elaboração pelos autores deste artigo.

Ressaltamos que as oito competências contidas na Matriz de Referência do novo Enem são suficientemente abrangentes para serem abarcadas em uma questão contextualizada, cujo conteúdo relevante expresse as "competências de inserção da ciência e de suas tecnologias em um processo histórico, social e cultural e o reconhecimento e a discussão de aspectos práticos e éticos da ciência no mundo contemporâneo" (BRASIL, 2002, p. 31). Para melhor expressarmos essa correspondência, a seguir, destacamos algumas possibilidades de articulação significativas para a contextualização que podem estar presentes nas questões:

- Conhecimento científico (CC): focaliza o domínio da física pelo estudante, o que conhece a respeito do conteúdo específico;

- Cotidiano (CO): focaliza situações do cotidiano das pessoas;

- Ciência e tecnologia (CT): explora aparatos, processos/produtos tecnológicos em relação com a ciência; 
- Meio ambiente (MA): focaliza impactos, preservação, deterioração do meio ambiente;

- Fenômeno natural (FN): fenômeno que ocorre naturalmente, podendo ou não ter sido decorrente da ação humana na natureza;

- História da ciência (HC): a questão ressalta o contexto histórico-social de determinado conhecimento científico;

- Experiência (EX): aborda a questão de um ponto de vista experimental;

- Situação-problema (SP): envolve uma situação codificada a ser interpretada de forma planejada, analisando-se o percurso da solução, vislumbrando uma tomada de atitude pelo estudante ${ }^{5}$.

Uma situação-problema, em um contexto de avaliação, define-se por uma questão que coloca um problema, ou seja, faz uma pergunta e oferece alternativas, das quais apenas uma corresponde ao que é certo quanto ao que foi enunciado. Para isso, a pessoa deve analisar o conteúdo proposto na situação-problema e, recorrendo às habilidades (ler, comparar, interpretar etc.), decidir sobre a alternativa que melhor expressa o que foi proposto (MACEDO, 2005, p. 30).

Essas diferentes formas de articulação, complementares entre si, conferem concretude à contextualização, de modo a "ser vista como uma competência geral, que transcende o domínio específico de cada uma das ciências” (BRASIL, 2002, p. 25).

O que se quer é o estabelecimento de uma intercomunicação efetiva entre as disciplinas, por meio do enriquecimento das relações entre elas. Almeja-se, no limite, a composição de um objeto comum, por meio dos objetos particulares de cada uma das disciplinas componentes (MACHADO, 2005, p. 49).

A promoção da aprendizagem interdisciplinar com contexto é defendida nos PCN+ (BRASIL, 2002) por meio da convergência de conhecimentos científicos e tecnológicos, buscando-se superar a disciplinaridade na produção do conhecimento. Nessas bases, uma questão do novo Enem pode ser classificada como (COSTA-BEBER; MALDANER, 2012):

Quadro 2: Classificação das questões do novo Enem segundo a interdisciplinaridade.

\begin{tabular}{|c|c|c|}
\hline Disciplinar & Parcialmente disciplinar & Interdisciplinar \\
\hline & Os conteúdos relevantes & Os conteúdos relevantes \\
estão articulados de forma & interconectados \\
estão compleúdos relevantes & complementar ou adjacente & de forma a dar sentido à \\
estruturados no âmbito de & a duas ou mais disciplinas; o & questão, e sua solução \\
uma disciplina. & conhecimento de uma delas & ével a partir de \\
& é suficiente para resolver a & conhecimentos de duas ou \\
& questão (física / outral. & mais disciplinas. \\
\hline
\end{tabular}

Fonte: Elaboração pelos autores deste artigo. 
Pinheiro e Ostermann (2010) realizaram uma análise comparativa das questões de física do novo Enem edição 2009 e do vestibular da Universidade Federal do Rio Grande do Sul (UFRGS) de 2009 e 2010. Os autores constataram que, apesar de o novo Enem enfatizar a contextualização, em sentido oposto ao assumido pelo vestibular da UFRGS, questões interdisciplinares estão muito pouco presentes (cerca de um quarto das questões de CNT).

Para o trabalho em sala de aula, na perspectiva da contextualização e da interdisciplinaridade, os $\mathrm{PCN}+$ propõem a organização curricular a partir de temas estruturadores do ensino, que "estruturam o conhecimento disciplinar e, ao mesmo tempo, são um espaço com ênfases e características próprias de promoção de competências e habilidades" (BRASIL, 2002, p. 21):

\begin{abstract}
As características comuns à Biologia, à Física, à Química e à Matemática recomendam uma articulação didática e pedagógica interna à sua área na condução do aprendizado, em salas de aula ou em outras atividades dos alunos. Procedimentos metodológicos comuns e linguagens compartilhadas permitem que as competências gerais, traduzidas para a especificidade da área, possam ser desenvolvidas em cada uma das disciplinas científicas e, organicamente, pelo seu conjunto. [...] organização e estruturação conjuntas dos temas e tópicos a serem enfatizados em cada etapa também facilitarão ações integradas entre elas, orientadas pelo projeto pedagógico da escola (BRASIL, 2002, p. 20).
\end{abstract}

Os Temas Estruturadores do Ensino de Física (TEEF) rompem com a tradicional fragmentação dos conteúdos escolares, ressignificando as subáreas da física (mecânica; física térmica; ondulatória e ótica; eletricidade e magnetismo; física moderna e contemporânea) e pautando a abordagem do conhecimento físico pelas competências e as habilidades necessárias à formação da cidadania (KAWAMURA; HOSOUME, 2003). Assim, os TEEF

devem estar relacionados, portanto, com a natureza e a relevância contemporânea dos processos e fenômenos físicos, cobrindo diferentes campos de fenômenos e diferentes formas de abordagem, privilegiando as características mais essenciais que dão consistência ao saber da Física e permitem um olhar investigativo sobre o mundo real (BRASIL, 2002, p. 69).

São seis temas estruturadores da física (BRASIL, 2002, p. 69-75), que podem ser organizados conforme o planejamento escolar, privilegiando uma abordagem epistemológica integradora: 1-Movimentos: variações e conservações; 2- Calor, meio ambiente e usos da energia; 3-Som, imagem e informação; 4-Equipamentos elétricos e telecomunicações; 5-Matéria e radiação; 6-Universo, Terra e vida.

Peixoto et al. (2009) identificaram temas relevantes nas questões de física do antigo Enem, no período 2005-2008, e sugeriram sua abordagem para o Ensino Médio na forma de questões abertas, numa perspectiva crítica e investigativa. Os autores enalteceram a importância do tema "energia", muito frequente nas provas (SILVA; PRESTES, 2009), para o desenvolvimento de projetos pedagógicos interdisciplinares, destacando o tema estruturador 2 (calor, ambiente e usos da energia) como central nessa abordagem. 
Após quatro anos do novo Enem, o acúmulo de questões relacionadas diretamente ou indiretamente à física permite percebermos regularidades na abordagem do conhecimento físico, como as observadas por Hernandes e Martins (2013). Assim sendo, verificar quais temas estruturadores referentes à física estão presentes nas provas de CNT pode oferecer pistas sobre quais orientações concretas as políticas públicas estão delimitando para o aperfeiçoamento dos currículos do Ensino Médio.

Em especial, interessa-nos verificar as questões que contemplam os princípios de interdisciplinaridade e contextualização pela via conceitual unificadora energética, proposta por Angotti (1993), para a organização do processo ensino-aprendizagem, de forma a romper com o currículo fragmentado que se pratica nas escolas. Esse autor propõe quatro conceitos unificadores, dois de primeira ordem (transformações e regularidades) e dois de segunda ordem (energia e escala), de caráter supradisciplinar, como estruturadores do conhecimento escolar, numa vertente epistêmica e numa perspectiva totalizadora. Esses conceitos constituem-se em balizas ou âncoras para o que é mais universal e geral, partilhado entre os conhecimentos das ciências naturais e das tecnologias.

O conceito unificador energia é o mais abstrato e abrangente, sendo, portanto, de segunda ordem e dependente dos de primeira ordem. Além de incorporar os dois primeiros,

é uma ponte segura que conecta os conhecimentos específicos de C\&T [Ciência e Tecnologia]. Conecta também esses a outras esferas de conhecimento, às contradições do cotidiano, permeado pelo natural, tanto fenomênico como tecnológico (ANGOTTI, 1993, v. 15, p. 195).

Guariglia et al. (2009) realizaram uma categorização das questões envolvendo o tema "energia" no antigo Enem, no período 2004-2008, e encontraram uma frequência significativa de questões em todos os anos, distribuídas em quatro categorias (produção de energia elétrica; economia financeira; temporalidade; políticas e fontes de energia menos poluentes), que surgiram da leitura e da análise das questões.

Desse modo, os autores perceberam a preocupação quanto à problemática atual da geração de energia no país, aos impactos e às projeções futuras e ressaltaram a necessidade de outras pesquisas, alargando e avaliando a pertinência do tema para o ensino de ciências. Essas observações também estão presentes no trabalho de Silva e Prestes (2009), cuja análise das questões referentes à física, nas provas de 2006 a 2008, abordou principalmente o conceito de energia em suas diversas formas e transformações, inclusive abordando fenômenos de interação da radiação eletromagnética com a matéria e aspectos de física nuclear.

Esse caminho alinhava, também, as competências e as habilidades avaliadas pelo novo Enem (HERNANDES; MARTINS, 2013), os TEEF e os princípios de interdisciplinaridade e contextualização presentes nos $\mathrm{PCN}+$, tendo em vista que estes sugerem abordagens didático-metodológicas na perspectiva totalizadora. 
Conceitos, como os de unidade, escala, transformação ou conservação, têm semelhanças e diferenças na forma com que são tratados pelas distintas ciências. Uma discussão geral de certos métodos, procedimentos e investigações, que são instrumental comum das várias ciências, pode ser ilustrada com a variedade de formas pelas quais desenvolvem os conceitos de igualdade e variação, de conservação e transformação ou, analogamente, de unidade e diversidade, de identidade e evolução, revelando elementos comuns ou distintos, sob codificações aparentemente idênticas (BRASIL, 2002, p. 24).

\section{$2^{\text {a }}$ PROBLEMATIZAÇ̃̃O}

Nossa estratégia metodológica, de caráter exploratório, consistiu num mapeamento da incidência dos conhecimentos de física, da contextualização e suas diferentes formas de articulação, da interdisciplinaridade e dos TEEF nas provas amarelas de CNT do Enem edições 2009c (prova cancelada em 2009), 2009, 2010, 2011 e 2012. Inicialmente, estabelecemos a seguinte relação de pertinência: quando os conteúdos da questão abordavam conceitos pertinentes à física que eram relevantes para a solução, de modo que o estudante necessitaria mobilizar ou operar esses conceitos, classificamos a questão como pertinente à física; uma questão cuja solução envolvia conceitos relacionados à física, mas não relevantes para a solução da questão ou que não influenciavam a solução foi classificada como parcialmente pertinente. Dessa forma, a tabela abaixo mostra o número de questões relacionadas à física presentes nas provas ao longo desses quatro anos.

Tabela 1: Número de questões envolvendo física nas provas de CNT/novo Enem (2009 a 2012)

\begin{tabular}{|c|c|c|c|c|c|c|}
\hline Pertinência à física & $\mathbf{2 0 0 9} \mathbf{c}^{*}$ & $\mathbf{2 0 0 9}$ & $\mathbf{2 0 1 0}$ & $\mathbf{2 0 1 1}$ & $\mathbf{2 0 1 2}$ & Total \\
\hline Pertinente & 13 & 15 & 11 & 13 & 16 & 68 \\
\hline $\begin{array}{c}\text { Parcialmente } \\
\text { pertinente }\end{array}$ & 2 & 4 & 4 & 1 & 1 & 12 \\
\hline Total & 15 & 19 & 15 & 14 & 17 & 80 \\
\hline
\end{tabular}

Observando a Tabela 1, verificamos que, do total de 225 questões de CNT nos cinco exames, 80 estão relacionadas, de algum modo, à física; há uma média de 16 questões por ano nas quatro provas aplicadas, aproximadamente $36 \%$ da prova de CNT. Nos primeiros dois anos, o percentual de questões envolvendo física nas quais o estudante precisaria mobilizar conceitos próprios da área questões pertinentes - girava em torno dos $82 \%$, mas esse percentual aumentou nos últimos dois anos, chegando a 94\% em 2012, ou seja, nesta edição, das 17 questões referentes a essa disciplina, 16 seriam resolvidas mobilizando-se ou operando-se conceitos de física. 
Diferentemente do que ocorre no período de transição entre o antigo e o novo Enem, representado nas provas de 2009, nas quais se destacam conhecimentos de física mais abrangentes (PEIXOTO; LINHARES, 2010; PINHEIRO; OSTERMANN, 2010), o exame tem privilegiado avaliar os conteúdos disciplinares da física comumente ensinados nas escolas (PEIXOTO; LINHARES, 2011). A Tabela 2 abaixo evidencia esse enfoque:

Tabela 2: Frequência das questões relacionadas à física nas provas CNT/novo Enem segundo grandes áreas de conhecimento escolar (2009 a 2012)

\begin{tabular}{|c|c|c|c|c|c|c|}
\hline Área da Física & $\mathbf{2 0 0 9 *}$ & $\mathbf{2 0 0 9}$ & $\mathbf{2 0 1 0}$ & $\mathbf{2 0 1 1}$ & $\mathbf{2 0 1 2}$ & Total \\
\hline Mecânica & 3 & 3 & 2 & 4 & 9 & 21 \\
\hline Termodinâmica & 5 & 6 & 5 & 1 & 1 & 18 \\
\hline $\begin{array}{c}\text { Óptica e } \\
\text { ondulatória }\end{array}$ & 2 & 3 & 2 & 4 & 3 & 14 \\
\hline Eletricidade & 4 & 7 & 6 & 4 & 3 & 24 \\
\hline Física moderna & 1 & - & - & 1 & 1 & 3 \\
\hline Total & 15 & 19 & 15 & 14 & 17 & 80 \\
\hline
\end{tabular}

*2009c: prova cancelada no ano 2009.

A Tabela 2 é reveladora da disciplinarização geradora de fragmentação no ensino de física. Notamos que as questões de mecânica vêm aumentando em número e proporcionalmente, de apenas três questões em 2009 para nove em 2012. Do total de 21 questões pertinentes a essa área, somente três se referem à astronomia, mesmo número alcançado pelas questões de física moderna. O número de questões referentes à termodinâmica decresceu ao longo dos anos, em média de cinco inicialmente para uma em 2012. Ondulatória e óptica mantiveram, juntas, a incidência em torno de três questões ao longo dos anos.

No que se refere à eletricidade, há presença significativa de questões dessa área em todos os anos, mas também há decréscimo em 2012. Devemos notar que verificamos a existência de apenas uma questão de eletromagnetismo ao longo dos quatro anos deste novo formato de prova e nenhuma de magnetismo (justificando-se, portanto, a categoria eletricidade, e não eletromagnetismo).

As questões nos últimos anos refletem o conjunto dos objetos de conhecimento presentes na matriz de referência do Enem (BRASIL, 2009). Contudo, nem as questões nem a matriz cobrem em extensão significativa os conhecimentos de CNT que permitem compreender o atual desenvolvimento técnico-científico, como é o caso da física moderna e contemporânea.

A Tabela 3 destaca a quantidade de questões classificadas como contextualizadas, parcialmente contextualizadas e não contextualizadas ao longo dos anos. 
Tabela 3: Frequência das questões envolvendo física nas provas CNT/novo Enem segundo a contextualização (2009 a 2012)

\begin{tabular}{|c|c|c|c|c|c|c|}
\hline Contextualização & 2009c* & $\mathbf{2 0 0 9}$ & $\mathbf{2 0 1 0}$ & $\mathbf{2 0 1 1}$ & $\mathbf{2 0 1 2}$ & Total \\
\hline Contextualizada & 10 & 10 & 9 & 6 & 15 & 50 \\
\hline $\begin{array}{c}\text { Parcialmente } \\
\text { contextualizada }\end{array}$ & 4 & 6 & 5 & 4 & 2 & 21 \\
\hline Não contextualizada & 1 & 3 & 1 & 4 & - & 9 \\
\hline Total & 15 & 19 & 15 & 14 & 17 & 80 \\
\hline
\end{tabular}

Podemos verificar que as questões não contextualizadas aparecem numa frequência muito pequena. As questões parcialmente contextualizadas correspondem a cerca de um terço das questões relacionadas à física em cada ano, com exceção de 2012. De fato, a maior parte das questões está contextualizada, chegando a 15 de um total de 17 questões em 2012. Isso revela o êxito do exame em estabelecer, no seu conjunto, uma rede de "relações vivenciadas e valorizadas no contexto em que se originam, na trama de relações em que a realidade é tecida" (MACHADO, 2005, p. 53). É importante verificarmos que articulações de diferentes contextos podem concorrer para isso, conforme expõem os dados da Tabela 4:

Tabela 4: Frequência das questões relacionadas à física nas provas CNT/novo Enem conforme a contextualização (2009-2012)

\begin{tabular}{|c|c|c|c|c|c|c|}
\hline $\begin{array}{c}\text { Formas de } \\
\text { contextualização }\end{array}$ & $2009 c^{*}$ & 2009 & 2010 & 2011 & 2012 & Total \\
\hline $\mathrm{CC}$ & 2 & 3 & 2 & 2 & - & 9 \\
\hline CC, EX & - & - & - & 1 & - & 1 \\
\hline $\mathrm{CO}, \mathrm{CC}$ & 1 & 2 & 4 & 1 & 6 & 14 \\
\hline CO, EX & - & - & 1 & 1 & & 2 \\
\hline $\mathrm{CO}, \mathrm{CT}$ & 2 & - & - & 1 & 2 & 5 \\
\hline $\mathrm{CO}, \mathrm{CT}, \mathrm{CC}$ & 4 & 4 & 1 & 1 & 3 & 13 \\
\hline $\mathrm{CO}, \mathrm{CT}, \mathrm{FN}$ & 1 & - & 1 & - & - & 2 \\
\hline $\mathrm{CO}, \mathrm{CT}, \mathrm{SP}$ & - & 2 & 1 & - & - & 3 \\
\hline $\mathrm{CO}, \mathrm{FN}, \mathrm{CC}$ & 1 & - & - & - & 1 & 2 \\
\hline $\mathrm{CO}, \mathrm{MA}, \mathrm{CC}$ & - & - & - & - & 1 & 1 \\
\hline CO, EX, CC & - & - & - & 1 & - & 1 \\
\hline CO, EX, CT & - & - & - & 1 & - & 1 \\
\hline $\mathrm{CO}, \mathrm{SP}, \mathrm{CC}$ & - & - & 1 & - & 2 & 3 \\
\hline $\mathrm{CT}, \mathrm{CC}$ & 3 & 4 & 3 & 3 & 1 & 14 \\
\hline $\mathrm{CT}, \mathrm{CC}, \mathrm{EX}$ & - & - & - & 1 & - & 1 \\
\hline $\mathrm{CT}, \mathrm{MA}$ & - & 1 & 1 & - & - & 2 \\
\hline $\mathrm{FN}, \mathrm{CC}, \mathrm{HC}$ & - & 1 & - & - & 1 & 2 \\
\hline $\mathrm{MA}, \mathrm{CC}$ & 1 & - & - & - & - & 1 \\
\hline $\mathrm{MA}, \mathrm{CO}, \mathrm{CT}$ & - & 1 & - & - & - & 1 \\
\hline $\mathrm{MA}, \mathrm{FN}, \mathrm{CC}$ & - & 1 & - & - & - & 1 \\
\hline MA, FN, CT & - & - & - & 1 & - & 1 \\
\hline Total & 15 & 19 & 15 & 14 & 17 & 80 \\
\hline
\end{tabular}

*2009c: prova cancelada no ano 2009. Legenda: CC- conhecimento científico; EX- situação experimental; CO- cotidiano; MA- meio ambiente; FN- fenômeno natural; CT- ciência e tecnologia; SP- situação-problema (problema vivencial). 
Percebemos nessa tabela um leque amplo de formas de contextualização presentes nas provas. Das 80 questões, apenas nove avaliam o conhecimento científico, e uma, articulando-o com uma situação experimental. Em geral, há uma preocupação dos elaboradores em articular diferentes formas de contextualização numa mesma questão. Assim, encontramos 46 questões referentes ao cotidiano das pessoas e 43 referentes ao par ciência-tecnologia, sendo 25 comuns às duas formas de contextualização.

Essa observação corrobora as realizadas por Peixoto e Linhares (2010, 2011) e Pinheiro e Ostermann (2010), referentes às primeiras provas do novo Enem, mas encontramos um número menor de questões que procuravam articular fenômenos naturais (FN), situações experimentais (SE) ou meio ambiente (MA). Esta última categoria se faz presente em todas as provas, mas com apenas uma questão em cada edição do Enem.

A contextualização a partir da história da ciência apareceu em uma questão de 2009 e outra de 2012, ambas, relacionadas à astronomia. Apenas sete questões mobilizaram conhecimentos da física para resolver situações-problemas, nas quais o estudante vislumbraria um problema de ordem prática, vivencial, em que precisava tomar uma decisão levando em conta o que conhecia a respeito da ciência ou de sua inter-relação com a tecnologia.

A Tabela 5 apresenta os dados de frequência das questões segundo a disciplinaridade ao longo dos anos, tendo-se em vista a necessidade de o exame incorporar esse princípio.

Tabela 5: Frequência das questões relacionadas à física nas provas CNT/novo Enem segundo a categoria disciplinaridade (2009-2012)

\begin{tabular}{|c|c|c|c|c|c|c|}
\hline Disciplinaridade & $\mathbf{2 0 0 9} \mathbf{c}^{*}$ & $\mathbf{2 0 0 9}$ & $\mathbf{2 0 1 0}$ & $\mathbf{2 0 1 1}$ & $\mathbf{2 0 1 2}$ & Total \\
\hline Disciplinar & 11 & 15 & 10 & 13 & 14 & 63 \\
\hline Parcialmente disciplinar & 4 & 3 & 3 & - & 3 & 13 \\
\hline Interdisciplinar & - & 1 & 2 & 1 & - & 4 \\
\hline Total & 15 & 19 & 15 & 14 & 17 & 80 \\
\hline
\end{tabular}

*2009c: prova cancelada no ano 2009.

Como podemos notar na tabela acima, o novo Enem tem privilegiado os conhecimentos disciplinares de física (PEIXOTO; LINHARES, 2011), numa média de 13 questões por ano cuja solução é encontrada mobilizando-se conhecimentos e conceitos próprios dessa disciplina. As questões que mobilizam, de algum modo, conhecimentos interdisciplinares, classificadas como parcialmente interdisciplinares, ocorrem numa frequência de cerca de três ao ano, com exceção de 2011, ano em que não encontramos nenhuma. As questões interdisciplinares aparecem numa frequência baixa, de uma e duas questões nos anos de 2009 a 2011, não ocorrendo em 2012. 
Podemos inferir que tem havido um novo direcionamento do Enem desde 2009, quando da publicação das Matrizes de Referência, as quais incorporam objetos de conhecimento que, no caso da física, praticamente sintetizam uma listagem de conteúdos tradicionalmente abordados nas escolas de Ensino Médio públicas. Com a implantação do Sisu, em 2010, as questões das provas de CNT referentes à física passaram a apresentar, em síntese, situações do cotidiano, abordando conhecimentos de mecânica de forma disciplinar. Maceno et al. (2011), ao analisarem a Matriz de Referência de 2009 e, em particular, suas possíveis repercussões no ensino da química, alertaram:

se o objetivo das reestruturações do Enem é o de induzir mudanças curriculares e pedagógicas, chamando à responsabilidade não só as escolas da educação básica, mas também as universidades quanto à formação básica e docente, esse anexo pode inviabilizar tal função, primeiro porque pode resgatar um tipo de ensino já em fase de superação, também porque é contraditório à própria proposta do exame tanto em relação ao desenvolvimento de eixos cognitivos, competências e habilidades bem como dos princípios da interdisciplinaridade e de contextualização. [...] Desse modo, a mudança preterida pelo Enem não alcançaria seu objetivo e contribuiria para que pouco fosse alterado nas práticas pedagógicas, uma vez que os professores, diante de tal lista, podem manter o ensino monodisciplinar e propedêutico (MACENO et al., p. 157).

Isso sugere que as tensões em torno da elaboração do exame e do acesso ao ensino superior e às políticas de assistência estudantil (Sisu, ProUni e outros programas) podem fazer transparecer as contradições entre o novo Enem e os objetivos e os fins da Educação Básica, expostos, por exemplo, nos $\mathrm{PCN}+$, relevando-se nuances da tradicional seleção realizada pelos vestibulares. Ainda assim, acreditamos que uma organização curricular baseada no desenvolvimento de competências e habilidades e alinhada com os PCN+ precisa ter o novo Enem como horizonte e referência. Consideramos necessário incluir, nos currículos escolares, estratégias de resolução aberta de questões desse exame nacional que privilegiem uma abordagem menos fragmentada dos conteúdos escolares de física pela via conceitual-unificadora do conhecimento em CNT (SOUZA et al., 2008).

Entendendo que os TEEF, enquanto balizadores do conhecimento escolar nas CNT do Ensino Médio, devem pautar esse caminho, destacamos na Tabela 6 em que medida tais temas estão presentes nas provas que analisamos. 
Tabela 6: Frequência dos TEEF nas provas de CNT/novo Enem (2009-2012)

\begin{tabular}{|c|c|c|c|c|c|c|}
\hline TEEF & $\mathbf{2 0 0 9 *}$ & $\mathbf{2 0 0 9}$ & $\mathbf{2 0 1 0}$ & $\mathbf{2 0 1 1}$ & $\mathbf{2 0 1 2}$ & Total \\
\hline 1 & 3 & 1 & 1 & 5 & 8 & 18 \\
\hline 2 & 6 & 7 & 5 & 2 & 2 & 22 \\
\hline 3 & 1 & 2 & 2 & 3 & 2 & 10 \\
\hline 4 & 3 & 6 & 6 & 3 & 2 & 20 \\
\hline 5 & 2 & 1 & - & 1 & 2 & 6 \\
\hline 6 & - & 2 & 1 & - & 1 & 4 \\
\hline Total & 15 & 19 & 15 & 14 & 17 & 80 \\
\hline
\end{tabular}

*2009c: prova cancelada no ano 2009

Os temas 2-calor, meio ambiente e usos da energia e 4-equipamentos elétricos e telecomunicações são responsáveis, cada um, por um quarto das questões de física, mas estão perdendo espaço para o tema 1 - movimento, variações e conservações desde 2011. Os temas 5-matéria e radiação e 6- universo, Terra e vida são pouco frequentes em todas as provas. A julgar pelos anos 2011-2012, o novo Enem, à medida que amplia a escala de atendimento a estudantes e auxílios, busca referenciar-se na dicotomia entre escola pública e vestibular.

É interessante desvelarmos, entretanto, outros aspectos relacionados ao que consideramos pertinente a uma política pública educacional de reestruturação do Ensino Médio na ótica dos documentos oficiais. Os TEEF 2 e 4 respondem por 11 das 12 questões parcialmente pertinentes à física, indicando que os conteúdos destas são mais abertos a outros campos de conhecimento. A Tabela 7, abaixo, evidencia essa situação do ponto de vista da interdisciplinaridade.

Tabela 7: Número de questões referentes aos TEEF segundo a disciplinaridade nas provas de CNT/novo Enem (2009-2012)

\begin{tabular}{|c|c|c|c|c|}
\hline TEEF & Disciplinar & $\begin{array}{c}\text { Parcialmente } \\
\text { Interdisciplinar }\end{array}$ & Interdisciplinar & Total \\
\hline 1 & 17 & 1 & - & 18 \\
\hline 2 & 12 & 8 & 2 & 22 \\
\hline 3 & 10 & - & 2 & 10 \\
\hline 4 & 16 & 2 & - & 6 \\
\hline 5 & 4 & 2 & - & 4 \\
\hline 6 & 4 & - & 4 & 80 \\
\hline Total & 63 & 13 & - & 20 \\
\hline
\end{tabular}


Podemos verificar na tabela acima que as questões interdisciplinares encontram-se nos TEEF 2 e 4, assim como a maioria das questões parcialmente interdisciplinares. O TEEF 2 apresenta o maior número de questões interdisciplinares ou parcialmente desse tipo: dez questões. Sinteticamente, esse tema propõe-se a desenvolver competências relacionadas aos modelos macro e microscópico do calor e às suas formas de uso, às variações climáticas e ambientais, reconhecendo a capacidade produtiva humana de aproveitamento das várias formas de energia, os impactos ambientais envolvidos, o funcionamento de máquinas térmicas e a compreensão das variações climáticas e ambientais (BRASIL, 2002; KAWAMURA; HOSOUME, 2003).

O TEEF 4 contém o maior número de questões numéricas, oito das 19 em todas as provas analisadas. Resumidamente, esse tema possibilita a compreensão dos fenômenos eletromagnéticos presentes no mundo vivencial e nos aparatos tecnológicos, desenvolvendo competências para dimensioná-los ou analisar as condições de sua utilização, destacando-se as questões relacionadas à produção e ao uso da energia elétrica e às telecomunicações (BRASIL, 2002; KAWAMURA; HOSOUME, 2003).

Se desejarmos produzir mudanças didático-pedagógicas introduzindo o novo Enem nas aulas de física, encontraremos nesses dois TEEF questões que articulam a contextualização e a interdisciplinaridade, explicitadas no quadro abaixo:

Quadro 3: Questões das provas de CNT do novo Enem relacionadas à física que articulam interdisciplinaridade, contextualização

\begin{tabular}{|c|c|c|c|c|c|}
\hline Prova amarela de CNT & $2009 c^{*}$ & 2009 & 2010 & 2011 & 2012 \\
\hline Questão & $1-35$ & $1-8-23$ & $57-60-$ & 78 & 85 \\
& & & $62-72-87$ & & \\
\hline
\end{tabular}

*2009c: prova cancelada no ano 2009.

Essas questões põem em evidência a natureza desses dois TEEF, que privilegiam os contextos da abordagem energética numa perspectiva unificadora, estabelecendo uma ponte segura para a articulação entre conhecimentos científicos e tecnológicos segundo a via dos universais da física (ANGOTTI, 1993), conforme se verifica nas questões analisadas nos trabalhos de Peixoto, Martins e Linhares (2009), Peixoto e Linhares (2010, 2011), Viggiano et al. (2011) e na categorização elaborada por Hernandes e Martins (2013).

São temas próprios para a problematização do par conteúdo-metodologia na formação inicial e continuada de professores de física e potencialmente geradores do desenvolvimento de estratégias de resolução aberta de problemas de física na perspectiva da educação científico-tecnológica. 


\section{CONSIDERAC̣ÕES FINAIS}

A democratização do acesso às universidades públicas do país é uma política pública educacional que se concretiza por meio de muitos esforços e caminhos. O novo Enem é uma estratégia válida dentro dessa política, na articulação e no diálogo entre sujeitos do ensino superior e da educação básica, de modo a revigorar os conhecimentos escolares e induzir mudanças nas práticas pedagógicas e na vida das pessoas (COSTA-BEBER; MALDANER, 2012). Essas mudanças são proporcionadas pela contextualização e a interdisciplinaridade, características validadas nas nossas análises anteriormente explicitadas com base nos exames nacionais realizados.

Afinal, exames nacionais e internacionais da aprendizagem escolar têm diagnosticado e sinalizado inovações necessárias aos currículos, ou seriam apenas instrumentos de validação das políticas públicas educacionais, como, por exemplo, a parametrização curricular nacional? Acreditamos que essa problematização seja essencial para a definição de projetos e programas de pesquisa-ação em ensino de física.

Percebemos um redirecionamento do novo Enem desde 2011, pois questões que mobilizam de algum modo conhecimentos interdisciplinares nos anos anteriores (cerca de quatro por ano) reduzem-se a uma questão interdisciplinar em 2011 e a três parcialmente interdisciplinares em 2012. As contradições revelam nuances da tradicional seleção de conteúdos escolares realizada pelas universidades. Nossas análises documentais indicam que a contextualização e a interdisciplinaridade, preconizadas na parametrização curricular nacional, não têm sido contempladas de forma prioritária.

Qual é a orientação dos contextos universitários públicos para os exames nacionais do Ensino Médio? Se o mapeamento anterior é merecedor de credibilidade, estamos retrocedendo para uma abordagem curricular disciplinar, cientificista e fragmentadora?

Acreditamos ter ressaltado, via validação analítica documental, que os TEEF 2- calor, meio ambiente e usos da energia e 4-equipamentos elétricos e telecomunicações, responsáveis, cada um, por cerca de um quarto das questões de física nas edições do Enem analisadas, são potencialmente significativos para planejarmos a resolução aberta de problemas segundo a via dos universais da física (SOUZA et al., 2008). Em especial, o conceito unificador energia emerge das questões pertencentes a esses TEEF, articulando os princípios de interdisciplinaridade e contextualização numa perspectiva totalizadora.

Energia, seja na forma de calor ou elétrica, relacionada ao meio ambiente, à tecnologia, à eletromagnética ou à telecomunicação, com excepcional potencial temático interdisciplinar e unificador, é tema bem-avaliado pelos pesquisadores da área de ensino de física para estruturar o Ensino Médio? Ou será que Temas Estruturadores do Ensino de Física mais próximos da hegemonia curricular da mecânica têm mais potencial inovador para unificar o conceitual do Ensino Médio em física? 
O novo Enem tem sinalizado que existem outros temas tão importantes quanto a mecânica para serem ensinados no Ensino Médio e numa perspectiva contrastante com a abordagem tradicional. Embora nossa análise sinalize o distanciamento de temas atuais, como a física moderna e contemporânea, o exame vem abrindo espaço para o debate em torno das contribuições da pesquisa em ensino de física/ciências para a melhoria desta área do ensino no país. Se isso, por um lado, valida nosso arcabouço analítico, por outro, coloca como desafio o desenvolvimento de questões de física contextualizadas e interdisciplinares no Exame Nacionais do Ensino Médio (Enem).

\section{NOTAS}

${ }^{1}$ Encerra conteúdos educacionais apresentados com contexto que requer a convergência de conhecimentos científicos e tecnológicos de mais de uma disciplina, buscando superar a fragmentação na produção do conhecimento (BRASIL, 2002).

${ }^{2}$ Consiste em desenvolver conhecimentos científicos e tecnológicos mediante conteúdos educacionais, apresentados com contexto que faça sentido para o aluno, fazendo imergir a ciência nos processos históricos, sociais e culturais, permitindo-lhe analisar como as situações se constituem e compreender como a atuação pode nelas interferir (BRASIL, 2002).

${ }^{3}$ Propõem uma organização curricular pautada em competências e habilidades para o trabalho em sala de aula no ensino médio, com a finalidade de apresentar com contexto os conhecimentos disciplinares. (BRASIL, 2002)

${ }^{4}$ Propõem a organização do processo de ensino-aprendizagem a partir de conceitos supradisciplinares, partilhados nas Ciências Naturais e suas Tecnologias, minimizando os excessos de fragmentação do conhecimento (ANGOTTI, 1993).

${ }^{5}$ Na perspectiva da Educação Dialógico-Problematizadora, realidade concreta é o contexto mais a visão que se tem dele. Não se trata apenas de situação-problema, mas de problema vinculado à realidade concreta dos envolvidos (contextualização), necessário para o desenvolvimento da conscientização, através da perspectiva interdisciplinar.

\section{REFERÊNCIAS}

ANGOTTI, J. A. P. Conceitos unificadores e ensino de Física. Revista Brasileira de Ensino de Física, São Paulo, v. 15, n. 1-4, p. $191-198,1993$.

BRASIL. Ministério da Educação. Secretaria da Educação Fundamental. Parâmetros Curriculares Nacionais do Ensino Médio. Brasília: MEC/SEF, 1999.

Ministério da Educação. Secretaria de Ensino Médio e Tecnológico. PCN+ Ensino Médio: orientações educacionais complementares aos Parâmetros Curriculares Nacionais. Ciências da Natureza, Matemática e suas Tecnologias. Brasília: MEC/Semtec, 2002. 
. Ministério da Educação. Instituto Nacional de Estudos e Pesquisas Anísio Teixeira. Matriz de Referencia para o Enem 2009. Brasília: MEC, 2009, 26p.

COSTA-BEBER, L. B.; MALDANER, O. A. O Novo Enem como instrumento de gestão e intervenção no sistema educacional: características de suas questões. In: ENCONTRO NACIONAL DE ENSINO DE QUÍMICA, 16., ENCONTRO DE EDUCAÇÃO QUÍMICA DA BAHIA, 10., 2012, Salvador. Anais... Salvador: SBQ, 2012.

GUARIGLIA, C. E. et al. Categorias de questões sobre energia no Enem. In: ENCONTRO DE PESQUISA EM ENSINO DE CIÊNCIAS, 7., 2006, Florianópolis. Atas... Florianópolis: Abrapec, 2009.

HERNANDES, J. S.; MARTINS, M. I. Categorização das questões de Física do Novo Enem. Caderno Brasileiro de Ensino de Física. Florianópolis, v. 30, n. 1, p. 58-83, 2013.

INSTITUTO NACIONAL DE ESTUDOS E PESQUISAS EDUCACIONAIS ANÍSIO TEIXEIRA (INEP). Exame Nacional do Ensino Médio (Enem): fundamentação teórico-metodológica. Brasília: O Instituto, 2005, $121 \mathrm{p}$.

KAWAMURA, M. R. D.; HOSOUME, Y. A contribuição da Física para um novo Ensino Médio. Física na Escola, São Paulo, v. 4, n. 2, 2003.

MACENO, N. et al. A matriz de referência do Enem 2009 e o desafio de recriar o currículo de química na educação básica. Química nova na escola, v. 33, n. 3, p. 153-159, 2011.

MACEDO, L. A situação-problema como avaliação e como aprendizagem. In: INEP. Exame Nacional do Ensino Médio (Enem): fundamentação teórico-metodológica. Brasília: O Instituto, 2005, 121 p.

MACHADO, N. J. Interdisciplinaridade e contextualização. In: INEP. Exame Nacional do Ensino Médio (Enem): fundamentação teórico-metodológica. Brasília: O Instituto, 2005, 121 p.

MINISTÉRIO DE EDUCAÇÃO (MEC), Portaria 807/2010, 2010.

MIRANDA E. M. et al. Enem 2009: articulações entre cts, interdisciplinaridade e contextualização evidenciadas nas questões das ciências da natureza. In: ENCONTRO DE PESQUISA EM ENSINO DE CIÊNCIAS, 8., CONGRESO INTERNACIONAL DE INVESTIGACIÓN EN ENSEÑANZA DE LAS CIENCIAS, 1., 2011, Campinas. Atas... Campinas: Abrapec, 2011.

PEIXOTO, K. C. Q. C. et al. Um olhar investigativo sobre as questões do Enem que abordam a Física. In: SIMPÓSIO NACIONAL DE ENSINO DE FÍSICA, 18., 2009. Vitória. Atas... Vitória: SBF, 2009.

PEIXOTO, K. C. Q. C.; LINHARES, M. P. Novo Enem: o que mudou? Uma investigação dos conceitos de física abordados no exame. In: ENCONTRO DE PESQUISA EM ENSINO DE FÍSICA, 12., 2010, Águas de Lindoia. Atas... Águas de Lindoia: SBF, 2010.

. A Física do Enem/2010. In: ENCONTRO DE PESQUISA EM ENSINO DE CIÊNCIAS, 8., CONGRESO INTERNACIONAL DE INVESTIGACIÓN EN ENSEÑANZA DE LAS CIENCIAS, 1., 2011, Campinas. Atas... Campinas: Abrapec, 2011.

PINHEIRO, N. C.; OSTERMANN, F. Uma análise comparativa das questões de física no novo Enem e em provas de vestibular no que se refere aos conceitos de interdisciplinaridade e de contextualização. In: ENCONTRO DE PESQUISA EM ENSINO DE FÍSICA, 12., 2010, Águas de Lindoia. Atas... Águas de Lindoia: SBF, 2010.

SILVA, A. M. M.; PRESTES, R. F. Conhecimentos de Física nas questões do Exame Nacional do Ensino Médio. In: SIMPÓSIO NACIONAL DE ENSINO DE FÍSICA, 18., 2009, Vitória. Atas... Vitória: SBF, 2009.

SOUZA, C. A et al. Resolução de problemas de física mediada por tecnologias. Caderno Brasileiro de Ensino de Física. Florianópolis, v. 25, nº 2, p. 310-339, 2008.

VIGGIANO E. et al. Uma investigação sobre o impacto do Sistema de Seleção Unificada nas questões sobre energia no Exame Nacional do Ensino Médio. In: ENCONTRO DE PESQUISA EM ENSINO DE CIÊNCIAS, 8., CONGRESO INTERNACIONAL DE INVESTIGACIÓN EN ENSEÑANZA DE LAS CIENCIAS, 1., 2011, Campinas. Atas... Campinas: Abrapec, 2011. 
Participação dos autores no artigo

Wagner Duarte José - procedeu à organização e à leitura do referencial teórico, ao levantamento e à análise dos dados, à redação e à revisão do artigo.

Graciely Rocha Braga - colaborou no levantamento e na análise dos dados.

Ana Quézia Brito Nascimento - colaborou no levantamento e na análise dos dados.

Fabio da Purificação de Bastos - colaborou na organização, na discussão, na redação e na revisão do artigo.

\section{Financiamento}

Universidade Estadual do Sudoeste da Bahia - UESB

Fundação de Amparo à Pesquisa do Estado da Bahia - FAPESB

Data Recebimento: 29/04/2014

Data Aprovação: 19/08/2014

Data Versão Final: 19/09/2014

\section{Contato:}

Wagner Duarte José

Universidade Estadual do Sudoeste da Bahia, Departamento de Ciências Exatas.

Estrada do Bem Querer, km 4, Caixa Postal 95

Jardim Candeias - Vitória da Conquista, BA - Brasil.

CEP: 45083900 Email: wagjose@gmail.com 